\section{Added value of bleach for tuberculosis microscopy diagnostic in limited resources setting}

Erike A. Suwarsono, ${ }^{1}$

Siti Nur Aisyah Jauharoh ${ }^{2}$

${ }^{1}$ Microbiology Department, ${ }^{2}$ Clinical Pathology Department, Faculty of Medicine, UIN Syarif Hidayatullah Jakarta, Indonesia

\begin{abstract}
Indonesia is one of the high burden tuberculosis (TB) countries. The utilization of molecular diagnostic has been setting over the country, however there are still a lot of remote areas that only depend on microscopic smear. Bleach might be used to increase the value of microscopy diagnostic. The study aimed to evaluate the added value of $1 \%$ bleach to increase the positivity rate of TB compared to conventional stain. This study was conducted on 70 subjects who were suspected as TB from various primary care centers in West Java and Banten, Indonesia. The sputum was $2-3 \mathrm{~mL}$, and divided into two parts, both of them were stained using Ziehl-Neelsen (ZN), however the first was only stained and the second added $1 \%$ bleach. Bleach was added in same volume with sputum and incubated for 10 minutes. After 10 minutes, the sputum was stained with $\mathrm{ZN}$. The positivity rate for $\mathrm{ZN}$ only was 39 (55.7\%) compared to $1 \%$ bleach was $63(90 \%)$, and significantly different $(\mathrm{P}=0.000)$ using Mann-Whitney $\mathrm{U}$ test. Bleach can be used as an alternative agent to improve the TB smear in setting that only depends on microscopy diagnostic.
\end{abstract}

\section{Introduction}

Tuberculosis (TB) is still one of major health problem around the globe, especially in developing country, such as Indonesia. According to WHO, Indonesia is one of 22 high burden TB countries, with moderatehigh prevalence of TB, TB-MDR and TBHIV. ${ }^{1}$ The Indonesian government already conducted a massive program in order to control TB infection, including set up a molecular diagnostic tool free of charges in many of health center. However, Indonesia is a big country with an archipelago geography, there are many of small islands and remote area that still lacks of TB diagnostic's capability and only depends on microscopy. The Ziehl-Neelsen (ZN) staining, an over 100 years old diagnostic method, has become most used technique, altough the sensitivity is variable. ${ }^{2}$ There are many methods to incerase the sensitivity of smear microscopy, including bleach. A previous study showed that bleach homogenisation and overnight sedimentation could increase the sensitivity, whereas another study found that centrifugation resulted in higher yields than sedimentation. ${ }^{3-5}$ However centrifugation and sedimentation need electricity and more advanced equipment, that may not meet in primary health care centers or limited resources health centers. This study was conducted to evaluate the use of $1 \%$ bleach to be added before $\mathrm{ZN}$ stain in order to increase the positivity rate of smear microscopy compared to $\mathrm{ZN}$ stain only. In this study, we used $1 \%$ bleach without centrifugation or any other technique to concentrate the sputum, because we want to make the technique easier to implement in limited resource setting.

\section{Materials and Methods}

In this study, 70 suspected new TB patients from several primary health cares in Bekasi and Tangerang Selatan region, Indonesia, were eligible. The sputum samples were collected after patient signed the informed consent during SeptemberDesember 2018. The study was approved by the ethical committee of Faculty of medicine UIN Syarif Hidayatullah Jakarta (the number of ethical clearance 617/UN2.F1/ETIK/VII/2018). All laboratory work was conducted in the microbiology laboratory of the Faculty of Medicine, UIN Syarif Hidayatullah Jakarta.

The patient submitted sputum in 2-3 $\mathrm{mL}$, and we divided the sputum into two parts. The first part for $\mathrm{ZN}$ stain and the second part for $\mathrm{ZN}$ added $1 \%$ bleach. The bleach added to the sputum in same value, and was shaked manually for less than a minute the closed tight the container, and incubated for 10 minutes in room temperature before stained by using $\mathrm{ZN}$. We carried out the $\mathrm{ZN}$ techique as previously described. ${ }^{6}$ We diluted $5.25 \%$ commercial bleach into $1 \%$ bleach and stored it in a dark bottle to avoid from direct sunlight. Each smear was examined by binocular microscopy (magnification x1000) on site by two different persons for validation. Each laboratory technician examined both
Correspondence: Erike A. Suwarsono, Faculty of Medicine, UIN Syarif Hidayatullah Jakarta. Jl. Kertamukti No. 5 Cirendeu, Ciputat Timur, Tangerang Selatan, Banten, 15412, Indonesia. Tel.: +62 (021) 74716718;

Mobile phone: +628165426218 .

E-mail: erike.suwarsono@uinjkt.ac.id

Key words: tuberculosis smear, ZiehlNeelsen, positivity rate, bleach.

Contributions: EAS, SAJ data collecting; EAS analyzing and manuscript writing; SAJ, manuscript reviewing.

Conflict of interest: The authors declare no potential conflict of interest.

Funding: The work was supported by Center of Research and Publication UIN Syarif Hidayatullah Jakarta Indonesia year 2018.

Acknowledgements: This study is supported by Grant of Center of Research and Publication UIN Syarif Hidayatullah Jakarta Indonesia.

Conference presentation: A part of this article has been presented at the International conference of Infectious Diseases, Biothreats and Millitary Medicine (INSBIOMM), 2019 August 27-28, Surabaya, Indonesia.

Received for publication: 17 February 2020. Accepted for publication: 1 July 2020.

This work is licensed under a Creative Commons Attribution-NonCommercial 4.0 International License (CC BY-NC 4.0).

CCopyright: the Author(s), 2020

Licensee PAGEPress, Italy

Infectious Disease Reports 2020; 12(s1):8719 doi:10.4081/idr.2020.8719

smears consecutively and validated each other blindly. The result was positive if there were more than one acid fast in 100 observations field be founded. The result was not categorized by IULTD's score $(1 / 2 / 3)$, however it was assigned qualitatively to positive or negative smear. For the internal quality, $100 \%$ positive and $10 \%$ of negative smear from bleach and non-bleach group were blindly reexamined by clinical microbiologist.

We compared the positivity rate between each group and analysed it statistically with Mann Whitney-U test to test statistical difference as the sample was paired specimen. We also made description for the characteristic's data of the subject whose sputum use in this study (Table 1). 


\section{Results}

From Table 1 we assumed that male subjects were more susceptible to be suspected TB infection and that chronic cough is still the main chief complaint in TB. On the other hand, as shown in Table 2, we found that the positivity result between $\mathrm{ZN}$ staining only versus added $1 \%$ bleach differed significantly. From the same table we can inference that added $1 \%$ bleach have greater positivity number that the $\mathrm{ZN}$ only.

The Figure 1 shows that the positivity rate of bleach $+\mathrm{ZN}$ is better than the $\mathrm{ZN}$ stain only. From the same figure we can assume that $1 \%$ bleach before $\mathrm{ZN}$ staining have better positivity rate rather than $\mathrm{ZN}$ only. Based on the result in Figure 2, we can inference that the smear from bleach with $\mathrm{ZN}$ has clearer background, and bleach can reduce the stickiness of the sputum. The clearer background will help us to find the red bacilli more easily.

\section{Discussion and Conclusions}

Based on the result of this study we can conclude that adding $1 \%$ bleach before preparing for $\mathrm{ZN}$ stain can improve the positivity rate of TB smear microscopy. From Table 2, we can see that 37 smears were positive and 29 were negative by both method (bleach and non-bleach respectively), 2 were negative by non-bleach but positive by bleach and vice versa. Both methods differ significantly, meaning that the preparation with $1 \%$ bleach was superior compare to ZN stain without bleach. The study conducted by Cattamanchi et al, concluded that bleach-processed smear increasing a small number of sensitivities compared to the direct smear, although there was no improvement on diagnostic accuracy. However Cattamanchi's study was limited on the heterogeneity of diagnostic accuracy for both direct and bleach microscopy. ${ }^{7}$

The higher positivity rate in $1 \%$ bleach can be seen clearly in the graph of Figure 1 ( $90 \%$ in $1 \%$ bleach vs $56 \%$ in non-bleach). The factor that may contribute to increase the positivity rate is the capability of bleach to digest the mucin and make the background clearer. ${ }^{8}$ The study by Bonnet et al. in Kenya within high risk population of HIV, showed that bleach sedimentation is an effective and simple method to improve microscopy result. As we can see from Figure 2, the smear background seemed clearer than direct smear, which is consistent with study from Kenya and Nigeria, as digested smear performed well and more
Table 1 . The subject's characteristics whose sputum were used in this study $(\mathrm{n}=70)$, both of them were processing with $\mathrm{ZN}$ only and $\mathrm{ZN}$ added bleach.

\begin{tabular}{lllcc} 
No & Characteristics & n & $\%$ \\
1 & Sex & Male & 40 & 57.1 \\
& & Female & 30 & 42.9 \\
& & 25 & 4 & 5.7 \\
& Age & $25-40$ & 28 & 40 \\
& & 38 & 54.3 \\
\hline 3 & Chief complain & Cough more than 2 weeks & 45 & 64.3 \\
& & Low fever last for 2 weeks & 10 & 14.3 \\
& & Lost of body weight & 10 & 14.3 \\
& & Others & 7.1 \\
\hline
\end{tabular}

Table 2. Cross-tabulation between $\mathrm{ZN}$ stain only and added $1 \%$ bleach-ZN stain.

\begin{tabular}{|c|c|c|c|}
\hline \multirow[t]{2}{*}{ ZN stain } & \multicolumn{2}{|c|}{$1 \%$ bleach-ZN } & \multirow[t]{2}{*}{ P* } \\
\hline & positive (n) & negative (n) & \\
\hline Positive (n) & 37 & 2 & $<0.000$ \\
\hline Negative (n) & 2 & 29 & \\
\hline
\end{tabular}

*Significant different using Mann-Whitney U test.

THE POSITIVITY RATE BETWEEN ZN ONLY AND $B L E A C H-Z N$

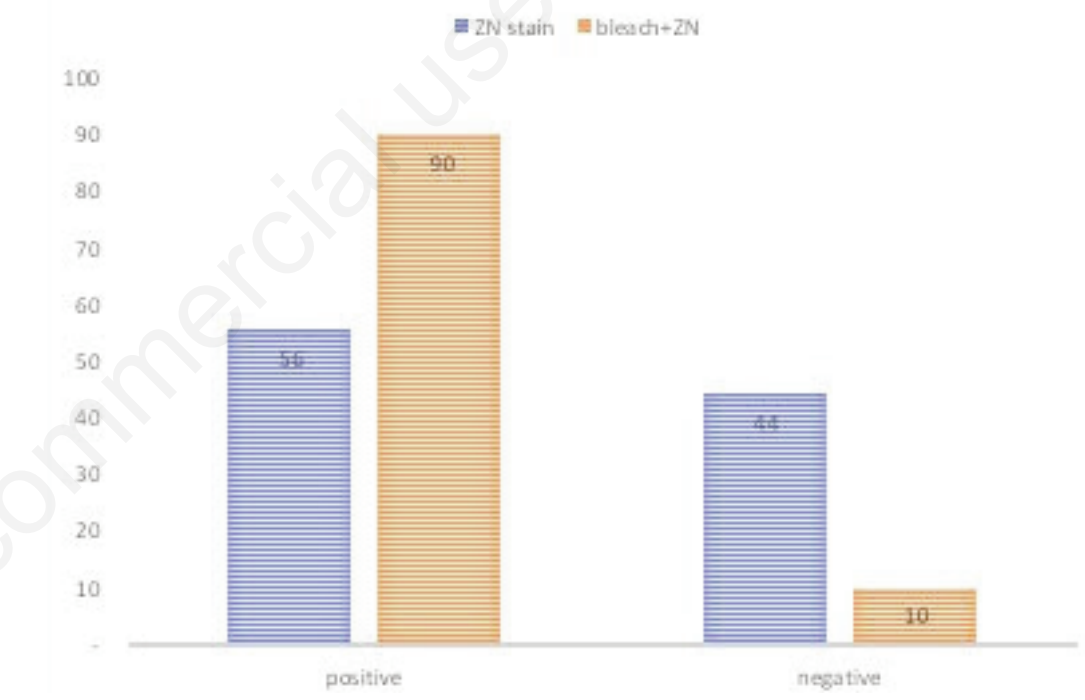

Figure 1. The positivity rate between $\mathrm{ZN}$ stain only and added $1 \%$ bleach-ZN stain in percentage value. (The positivity rate of $\mathrm{ZN}$ only is lower than bleach- $\mathrm{ZN}-56 \%$ vs 90\%).

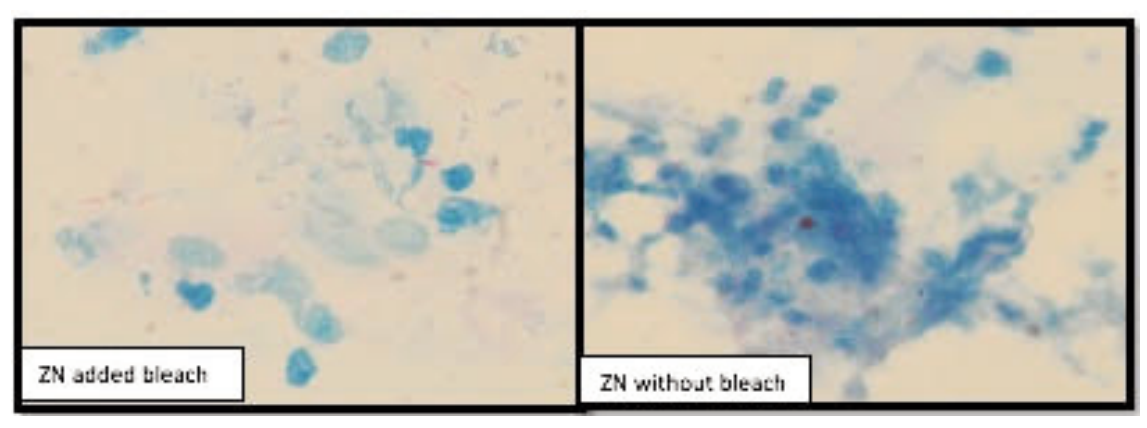

Figure 2. The smear's result from added $1 \%$ bleach with $\mathrm{ZN}$ (left) and $\mathrm{ZN}$ staining only (right) from same specimen. We can see the background of $1 \%$ bleach is clearer than $\mathrm{ZN}$ only, so we can find the bacilli more easily. 
positive result than direct smear. ${ }^{8,9}$

David et al. argued that bleachprocessed sputum is an alternative to current diagnostic practice in low resource settings. ${ }^{10}$ The study was conducted using $5 \%$ $\mathrm{NaOCl}$ for 15 minutes incubation and centrifugation, thus the bleach-processed smear yield a higher result as $15.4 \%$ and there was no loss of positive result compared to nonbleach processed smear. ${ }^{10}$ Compared to this study, the $1 \%$ bleach-processed group yield a $34 \%$ higher rate than the non-bleach smear, bigger number of positive result than previous study with smaller concentration and non-centrifugation method.

The method in this study is simple, inexpensive and can be completed in a short period of time, compared to other studies that use centrifugation and overnight incubation. ${ }^{8,10,11}$ We only incubated the sputum for 10 minutes and no other advanced instrument was used. The main reagent, commercial bleach, is affordable and available even in very remote areas and can be used in limited setting, where tuberculosis is endemic, like Indonesia. However, as the background seems clearer because of lack of the background material, our technicians complained difficult in focusing. This limitation is similar with those mentioned in the previous study by Bonnet. ${ }^{8}$ Bonnet also considered the possibility of smear washing out during slide staining, although we didn't find any difficulties regarding this issues because we only incubated for 10 minutes while Bonnet did overnight sedimentation. ${ }^{8}$ The concentration in Bonnet's study was higher than our concentration, as they used $3.5 \%$ and we used only $1 \%$, therefore this lower concentration may lead to less sputum liquefaction.

The diagnosis of tuberculosis depends on high standard biosafety for bacilli culture, however in limited resources setting, the condition is difficult to meet. We must find a safer method in conducting TB diagnostic with high positivity rate. This study doesn't need any centrifugation, so there are no aerosol sparks during laboratory work. The sample was manually shaken and the sputum container didn't open until 10 minutes after, that is our incubation period, thus the bacilli and aerosol sparks could be minimized. Bleach, is also known as an effective disinfectant, and can be used to minimize the transmission of Mycobacterium tuberculosis bacilli to the laboratory workers. ${ }^{12,13}$ Chew concluded in his study that bleach concentration before staining procedure can be used to sterilize the sputum from the Mycobacterium tuberculosis bacil1i. ${ }^{5}$ However, the limitation of this study was not counting the score of AFB, so the differentiation only based on the positive or negative appearance of the bacilli.

Other studies said that bleach-processed sputum still compatible with PCR-based method and bacilli culture in highly contaminated sputum. ${ }^{10,14}$ As far as the first method is concerned, the nucleic acid component still can be examined, tough the microorganism is dead, ${ }^{15}$ and for bacilli culture, bleach is prominent to minimize the other bacteria instead of Mycobacterium tuberculosis. ${ }^{14,16}$ As the bleach is inexpensive it is likely to implement the accuracy of TB smear diagnostic in developing or low income countries. By those result, we can use bleach-processed smear as an alternative for TB diagnostic in limited setting or remote area.

\section{References}

1. WHO. Global Tuberculosis Report 2014. WHO Rep 2014;2014;:171.

2. Fitzgerald Daniel W, Starling Timothy R HDW. Mycobacterium tuberculosis. 8th Ed. Elsevier Inc; 2010.

3. Hepple P, Nguele P, Greig J, et al. Direct microscopy versus sputum cytology analysis and bleach sedimentation for diagnosis of tuberculosis: a prospective diagnostic study. BMC Infect Dis 2010;10:276.

4. Singhal R, Myneedu VP. Microscopy as a diagnostic tool in pulmonary tuberculosis. Int J Mycobacteriology 2015;4:16.

5. Chew R, Calderón C, Schumacher SG, et al. Evaluation of bleach-sedimentation for sterilising and concentrating Mycobacterium tuberculosis in sputum specimens. BMC Infect Dis 2011; 11:269.

6. Pyffer GE, Palicova F. Mycobacterium : General Characteristics, Laboratory Detection and Staining Procedurs. Manual of Clinical Microbiology 2011;472-524.

7. Cattamanchi A, Davis JL, Pai M, et al.
Does bleach processing increase the accuracy of sputum smear microscopy for diagnosing pulmonary tuberculosis? J Clin Microbiol 2010;48:2433-9.

8. Bonnet M, Ramsay A, Githui W, et al. Bleach sedimentation: an opportunity to optimize smear microscopy for tuberculosis diagnosis in settings of high prevalence of HIV. Clin Infect Dis 2008;46: 1710-6.

9. Bonnet M, Tajahmady A, Hepple P, et al. Added value of bleach sedimentation microscopy for diagnosis of tuberculosis: A cost-effectiveness study. Int J Tuberc Lung Dis 2010;14:571-7.

10. David S, Sutre AF, Sanca A, et al. Tuberculosis diagnosis after bleach processing for early stage tuberculosis laboratory capacity building. Int J Tuberc Lung Dis 2012;16:1535-7.

11. Van Deun A, Kya Maug A, Cooreman E, et al. Bleach sedimenation method for increased sensitivity of sputum smear microscopy: does it work? Int J Tuberc Lung Dis 2000;4:371-6.

12. Yassin MA, Cuevas LE, Gebrexabher $\mathrm{H}$, Squire SB. Efficacy and safety of short-term bleach digestion of sputum in case-finding for pulmonary tuberculosis in Ethiopia. Int J Tuberc Lung Dis 2003;7:678-83.

13. Chew R, Calderón C, Schumacher SG, et al. Evaluation of bleach-sedimentation for sterilising and concentrating Mycobacterium tuberculosis in sputum specimens. BMC Infect Dis 2011; 11:269.

14. Suwarsono EA, Karuniawati A, Sjahrurachman A, Burhan E. The Evaluations of Bleach as Decontaminant Solution to Promote The Positivity Rate of Mycobacterium Tuberculosis Culture for Sputum Specimen. Adv Health Sci Res 2017; 10:23-6.

15. Winter J, Ilbert M, Graf PCF, et al. Bleach Activates a Redox-Regulated Chaperone by Oxidative Protein Unfolding. Cell 2008;135:691-701.

16. Suwarsono EA, Sjahrurachman A, Karuniawati A, Burhan E. The Effect of Several Different Decontaminant Solutions for Sputum in Inhibiting Contamination of Mycobacterium Tuberculosis Culture. Adv Sci Lett 2018;24:6930-3. 